\title{
LEITURA DE IMAGENS, CULTURA VISUAL E PRÁTICA EDUCATIVA
}

\author{
MARIA EMILIA SARDELICH \\ Departamento de Educação da Universidade Estadual de Feira de Santana - BA \\ emilisar@hotmail.com
}

\begin{abstract}
RESUMO
Quase tudo do pouco que sabemos sobre o conhecimento produzido nos chega pelos meios de informação e comunicação. Estes, por sua vez, também constroem imagens do mundo. Imagens para deleitar, entreter, vender, sugerindo o que devemos vestir, comer, aparentar, pensar. Em nossa sociedade contemporânea discute-se a necessidade de uma alfabetização visual, que se expressa em várias designações, como leitura de imagens e compreensão crítica da cultura visual. Freqüentes mudanças de expressões e conceitos dificultam o entendimento dessas propostas para o currículo escolar, assim como a própría definição do professor ou professora que será responsável por esse conhecimento e seu referencial teórico. Este artigo apresenta os conceitos que fundamentam as propostas da leitura de imagens e cultura visual, sinalizando suas proximidades e distâncias. Contrasta alguns referenciais teóricos da antropologia, arte, educação, história, sociologia, e sugere linhas de trabalho em ambientes de aprendizagem para que se possa refletir a permanente formação docente. MEIOS DE COMUNICAÇÃO DE MASSA - PRÁTICA DE ENSINO - ARTE - CULTURA
\end{abstract}

\section{ABSTRACT}

IMAGE READING, VISUAL CULTUREAND EDUCATIONAL PRACTICE. Nearly everything of the little we know about the produced knowledge reaches us through the means of information and communication. These, on their turn, also build world images. Images to delight, entertain, and sell, suggesting what we should dress, eat, look like and think. In our contemporary society, it is discussed the need for a visual alphabetization that takes on several names, such as image reading and critical understanding of the visual culture. Frequent changes in expressions and concepts hamper the understanding of these proposals for school

Este artigo é fruto de uma investigação mais ampla, intitulada Eduweb e cultura visual: um contraste entre práticas artísticas e educativas em rede, desenvolvida pela autora em 2003-2004 como professora visitante do Programa de Doutorado Educación Artística: Enseñanza y Aprendizaje de las Artes Visuales, da Faculdade de Belas Artes da Universidade de Barcelona. 
curriculum, as well as the definition of the teacher who will be in charge for this knowledge and its theoretical frame of reference. This article presents the concepts that justify proposals of image reading and visual culture, signaling their closeness and distances. It also compares some theoretical backgrounds related to anthropology, art, education, history and sociology, suggesting lines of work within learning environments, so that we can reflect about our permanent training as teachers.

MASS MEDIA - EDUCATIONAL PRACTICE - ART - CULTURE

Na vida contemporânea, quase tudo do pouco que sabemos sobre o conhecimento produzido nos chega via Tecnologias da Informação e Comunicação TIC - que, por sua vez, constroem imagens do mundo. Nômades em nossas próprias casas, capturamos imagens, muitas vezes sem modelo, sem fundo, cópias de cópias, no cruzamento de inúmeras significações. Imagens para deleitar, entreter, vender, que nos dizem o que vestir, comer, aparentar, pensar.

O crescente interesse pelo visual tem levado historiadoras/es, antropólogas/os, sociólogas/os, educadoras/es a discutirem sobre as imagens e sobre a necessidade de uma alfabetização visual, que se expressa em diferentes designações, como leitura de imagens e cultura visual. Podemos nos perguntar sobre o porquê de uma cultura visual. Essa cultura exclui o não-visual e/ou aqueles que são privados desse sentido? A proposta da cultura visual é a mesma da leitura de imagens? Podemos utilizar as duas expressões como sinônimas? Que professor/a pode desenvolver essas atividades no contexto escolar? A cultura visual não será mais uma designação, entre tantas outras, para confundir as/os professoras/es?

Annateresa Fabris ( 1998) nos auxilia a compreender o interesse pelo visual no mundo contemporâneo. Segundo ela, a imagem especular, própria do Renascimento, não é apenas resultado de uma ação artística, mas sim fruto de um cruzamento entre arte e ciência. Sua perspectiva vai muito além da mera aplicação de leis geométricas e matemáticas, pois se trata de um modelo de organização e racionalização de um espaço hierárquico. É a possibilidade de estruturar o espaço a partir de um determinado ponto de vista, aquele de um sujeito onisciente, capaz de tudo dominar e determinar. A autora mostra que o lapso de tempo em que o artista do Renascimento organizava uma nova visualidade coincide com o desenvolvimento da imprensa, com um novo modo de armazenar e distribuir um conhecimento interessado na preservação do passado e na difusão do presente. Nesse período, buscava-se um novo estilo 
cognitivo baseado na demonstração visual. As imagens com perspectiva eram uma tentativa de tornar o mundo compreensível à poderosa figura que permanecia em pé, no centro da imagem, no único ponto a partir do qual era desenhada. Esse estilo cognitivo perdurou até a fotografia e a videoeletrônica. Mas hoje, com as tecnologias disponíveis no mundo contemporâneo, que estão redefinindo os conceitos de espaço, tempo, memória, produção e distribuição do conhecimento, estamos em busca de uma outra epistemologia, e se necessitamos de outro modo de pensamento, conseqüentemente necessitamos também de outra visualidade.

Neste artigo, proponho desenredar os conceitos de leitura de imagens e cultura visual, sinalizando suas proximidades e distâncias para sua aplicação à prática educativa. Por meio do contraste entre referenciais teóricos da antropologia, arte, educação, história e sociologia, sugiro linhas de trabalho em ambientes de aprendizagem com o intuito de contribuir para a reflexão que envolve nossa permanente formação como docentes.

\section{LEITURA DE IMAGENS}

A expressão leitura de imagens começou a circular na área de comunicação e artes no final da década de 1970, com a explosão dos sistemas audiovisuais. Essa tendência foi influenciada pelo formalismo, fundamentado na teoria da Gestalt, e pela semiótica. Na psicologia da forma, a imagem constituia percepção, já que toda experiência estética, seja de produção ou recepção, supõe um processo perceptivo. A percepção é entendida aqui como uma elaboração ativa, uma complexa experiência que transforma a informação recebida.

$\mathrm{Na}$ medida em que a imagem passa a ser compreendida como signo que incorpora diversos códigos, sua leitura requer o conhecimento e a compreensão desses códigos. Essa idéia de "ensinar a ver e ler" os dados visuais inspirou-se no trabalho de Rudolf Arnheim, Art and visual perception, de 1957', que procura identificar as categorias visuais básicas mediante as quais a percepção deduz estruturas e o produtor de imagens elabora suas configurações. Arnheim catalogou dez categorias visuais: equilíbrio, figura, forma, desenvolvimento,

I. Edição brasileira, Arnheim ( 1989). 
espaço, luz, cor, movimento, dinâmica e expressão. Nesse modelo o espectador desvela nas imagens os esquemas básicos utilizando as várias categorias visuais até descobrir a configuração que, por si mesma, possui qualidades expressivas. No Brasil, Fayga Ostrower (1983, 1987, 1990) foi uma das divulgadoras dos trabalhos de Rudolf Arnheim. As idéias desenvolvidas por Ostrower em cursos e encontros com professores enfatizavam as relações entre os aspectos formais e expressivos das imagens.

Outra obra que fundamentou a tendência formalista da leitura de imagens foi a da desenhista Donis Dondis, A primer of visual literacy, publicada em 1973 pelo Masschusetts Institute of Technology², na qual a autora introduz o conceito de alfabetismo visual. O livro propõe um sistema básico para a aprendizagem, identificação, criação e compreensão de mensagens visuais acessíveis a todas as pessoas, e não somente àquelas especialmente formadas como projetistas, artistas e estetas. Apoiando-se no sistema proposto por Dondis para uma "alfabetização visual", alguns professores começaram a aplicar um esquema de leitura de imagens fundamentado na sintaxe visual, que mostra a disposição dos elementos básicos, como ponto, linha, forma, cor, luz, no sentido da composição.

A proposta da leitura de imagens de tendência formalista fundamentase em uma "racionalidade" perceptiva e comunicativa que justifica o uso e desenvolvimento da linguagem visual para facilitar a comunicação. No contexto escolar, essa prática era atribuída geralmente a professoras/es de arte, porém, não chegou a ser hegemônica entre eles. Hernandez (2000) chama de "racionalidade" o conjunto de argumentos e evidências que justificam a inserção da prática artística no contexto escolar. A presença de uma racionalidade não representa necessariamente uma hegemonia, pois diferentes formas de racionalidade podem conviver no mesmo espaço e tempo, e uma pode estar mais consolidada que outra. A racionalidade moral entende que a prática artística contribui para a educação moral e o cultivo da vida espiritual e emocional. A racionalidade expressiva considera a arte essencial para a projeção de emoções e sentimentos que não poderiam ser comunicados de nenhuma outra forma. Concebe-se a prática artística como uma forma de conhecimento que favore-

2. Edição brasileira, Dondis (199|). 
ce o desenvolvimento intelectual para a racionalidade cognitiva. Por fim, a racionalidade cultural entende o fenômeno artístico como manifestação cultural, e vê nos artistas os responsáveis por realizar as representações mediadoras de significados para cada época e cultura. Essa forma de racionalidade está presente nos Parâmetros Curriculares Nacionais - PCN -, que definem o objeto artístico, no caso as imagens, como produção cultural, documento do imaginário humano, de sua historicidade e de sua diversidade (Brasil, 1997, p. 45).

Outras abordagens, mais voltadas para o aspecto estético da leitura de imagens de obras de arte, apóiam-se nas investigações de Ott (1984), Housen ( 1992 ) e Parsons ( 1 992). No Brasil, o sistema de apreciação de Ott encontrou ressonância a partir de sua apresentação em um curso promovido pelo Museu de Arte Contemporânea da Universidade de São Paulo, em 1988. Robert Willian Ott, professor da Universidade da Pensilvânia, Estados Unidos, desenvolveu a metodologia image watching [olhando imagens] com o intuito de estruturar a relação do apreciador com a obra de arte. Sua metodologia foi configurando-se em função dos desafios que enfrentava como professor responsável pela prática de ensino e de estágio supervisionado, no departamento de arte e educação de sua universidade, diante de uma platéia heterogênea quanto ao conhecimento e às vivências artísticas e museológicas. Inspirado em John Dewey e Edmund Feldman, Ott utilizou o gerúndio (watching) para nomear seu sistema de apreciação, para deixar claro que se tratava de um processo, articulado em seis momentos:

- aquecendo (ou sensibilizando): o educador prepara o potencial de percepção e de fruição do educando;

- descrevendo: o educador questiona sobre o que o educando vê, percebe;

- analisando: o educador apresenta aspectos conceituais da análise formal;

- interpretando: o educando expressa suas sensações, emoções e idéias, oferece suas respostas pessoais à obra de arte;

- fundamentando: o educador oferece elementos da História da Arte, amplia o conhecimento e não o convencimento do educando a respeito do valor da obra;

- revelando: o educando revela através do fazer artístico o processo vivenciado. 
Os estudos de Abigail Housen partem do postulado de que o desenvolvimento em determinado domínio se faz em direção a maior complexidade do pensamento, configurando estágios desse desenvolvimento. Assim, as habilidades para a compreensão estética crescem cumulativamente à medida que o leitor vai evoluindo ao longo dos estágios: narrativo, construtivo, classificativo, interpretativo e recriativo. Nessa mesma linha de raciocínio, Michael Parsons afirma que um grupo de idéias, de tópicos estéticos (tema, expressão, aspectos formais, juízo) prevalece e é entendido de maneira cada vez mais complexa, do ponto de vista estético, em cada um dos estágios de desenvolvimento. Ambos os autores concordam que nem todos os adultos alcançam os estágios mais elevados de compreensão estética, pois o que mais favorece o desenvolvimento estético é a familiaridade com as imagens das obras de arte, e isso depende das experiências artísticas de cada pessoa.

trabalho de Rossi (2003), apoiado nos estudos de Parsons, sustenta que uma atividade de leitura de imagens deve considerar o desenvolvimento psicológico e a familiaridade do leitor com as imagens a serem lidas. No entanto, Rossi não utiliza apenas imagens do mundo da arte, como Parsons, mas lança mão também daquelas vindas também da publicidade. Critica o enfoque formalista de leitura estética que, segundo ela, vem sendo priorizado no ensino de arte no Brasil, e que contaminou a educação básica, reduzindo-se a um roteiro preestabelecido de perguntas que não respeita a construção dos leitores nesse domínio.

A faceta semiótica introduziu no modelo de leitura da imagem as noções de denotação e conotação. A denotação refere-se ao significado entendido "objetivamente", ou seja, o que se vê na imagem "objetivamente", a descrição das situações, figuras, pessoas e ou ações em um espaço e tempo determinados. A conotação refere-se às apreciações do intérprete, aquilo que a imagem sugere e/ou faz pensar o leitor. Esse modelo vem sendo utilizado por alguns professores que propõem a leitura de imagens da arte (Santibáñez, Valgañón, 2000; Cruz, 200 I), ou da publicidade (Joly, 1996; Barret, 2003). A abordagem formalista, influenciada pela semiótica, enfatiza a leitura da imagem a partir dos seguintes códigos:

- espacial: o ponto de vista do qual se contempla a realidade (acima/ abaixo; esquerda/direita; fidelidade/deformação); 
- gestual e cenográfico: sensações que produzem em nós os gestos das figuras que aparecem (tranqüilidade, nervosismo, vestuário, maquiagem, cenário);

- Iumínico: a fonte de luz (de frente achata as figuras que ganham um aspecto irreal, de cima para baixo acentua os volumes, de baixo para cima produz deformações inquietantes);

- simbólico: convenções (a pomba simboliza a paz; a caveira, a morte);

- gráfico: as imagens são tomadas de perto, de longe;

- relacional: relações espaciais que criam um itinerário para o olhar no jogo de tensões, equilíbrios, paralelismos, antagonismos e complementaridades.

De outro ponto de vista, antropólogos, sociólogos e historiadores interessam-se pelo uso de imagens como fonte documental, instrumento, produto de pesquisa, ou ainda, como veículo de intervenção político-cultural (Feldman-Bianco, Leite, 1998). Diante dessas novas perspectivas teórico-metodológicas, reforça-se a tendência a construir o conhecimento utilizando a dimensão imagética como documento. $\bigcirc$ uso de imagens na pesquisa histórica é crescente, apesar do baixo número de pesquisadores "alfabetizados visualmente" (Samain, 1998) e das dificuldades e limites que o âmbito acadêmico impõe a esse tipo de pesquisa. Uma dessas dificuldades é a resistência de alguns teóricos a aceitar a aproximação, o rascunho, o movente, a criação, a imaginação e os sentimentos como campos que tecem o itinerário argumentativo do conhecimento (Cunha, 200I).

Cardoso e Maud ( 1997) advertem que o pesquisador que lida com as imagens tende a reagir inicialmente com o mesmo encantamento que reage diante das relíquias e cortes do passado que o tempo não extinguiu. Ler uma imagem historicamente é mais do que apreciar o seu esqueleto aparente, pois ela é construção histórica em determinado momento e lugar, e quase sempre foi pensada e planejada. Por exemplo, tanto fotógrafos como pintores negociam o cenário das imagens que produzem, mas essa negociação não é aleatória, pois visa um público e o que se quer mostrar a este público. O cenário preparado aproxima a imagem de outros interesses ou intenções como, por exemplo, o de apresentar uma determinada realidade e/ou alteração da realidade. No entanto, mesmo que se constitua uma realidade montada e/ou uma 
alteração dela, fruto da imaginação de um ou mais componentes, a imagem fixada não existe fora de um contexto, de uma situação. Pedaços desse contexto são encontrados tanto no interior da imagem quanto no seu exterior. $\bigcirc$ interior corresponderia ao próprio cenário, com seus utensílios e apetrechos, as pessoas com suas roupas, cabelos, modos e posturas corporais. $\bigcirc$ exterior corresponderia ao próprio suporte da imagem, às técnicas de produção no momento da criação, como também às perspectivas que tal novidade técnica gerou ou não nas pessoas em geral.

Trabalhando no campo historiográfico, Leite (1996) afirma que a imagem não comunica com clareza pois pode forjar realidades, e por isso são necessários constantes e insistentes olhares, aliados à disposição dos sentidos para captar aquilo que não vemos na superfície, a fim de discernir outros conteúdos que ultrapassem a primeira impressão que se tenta impor ou estabelecer. Para que a amplitude de possibilidades da fonte iconográfica não se transforme num empecilho, a autora indica dois elementos decisivos para a leitura da imagem: o primeiro é ter um bom conhecimento de base técnica e o segundo é dispor de uma boa dose de criação artística. Segundo ela, "decifrar" uma mensagem visual é uma tarefa que pode ser iniciada pelo conteúdo manifesto, pela unanimidade de compreensão, sem deixar de considerar o conteúdo latente. No conteúdo manifesto, as contradições e os conflitos são em geral pouco observados, conforme as expectativas dos responsáveis pela imagem, não só do seu produtor, mas também daquele que encomendou a obra. Caminhando para a fase dos conteúdos latentes, é preciso buscar informações fundamentais que respondam a perguntas do tipo: como as imagens foram geradas? por quem? para quem? por quê?

No âmbito da documentação, Valle Gastaminza (2002) refere-se às indicações para catalogar uma imagem, e afirma que uma leitura inteligente da imagem, seja o leitor um documentalista ou não, requer as seguintes competências:

- iconográfica: reconhecer formas visuais que reproduzem ou não algo que existe na realidade;

- narrativa: estabelecer uma seqüência narrativa entre elementos que aparecem na imagem e/ou elementos de informação complementar (título, data, local etc.); 
- estética: atribuir sentido estético à composição;

- enciclopédica: identificar personagens, situações, contextos e conotações;

- lingüístico-comunicativa: atribuir um tema, um assunto que poderá contrapor-se ou coincidir com as informações complementares;

- modal: interpretar o espaço e tempo da imagem.

A abordagem da leitura crítica das imagens de Kellner ( 1995) influenciou o trabalho de educadores que se reportam a uma pedagogia da imagem. A pedagogia da imagem situa-se no marco teórico dos Estudos Culturais, e considera que a educação não se restringe às formas legais organizadas quase sempre na instituição escolar. Em qualquer sociedade há inúmeros mecanismos educativos presentes em diferentes instâncias socioculturais. Grande parte desses mecanismos tem como função primeira educar os sujeitos para que vivam de acordo com regras estabelecidas socialmente. Por estarem inseridos na área cultural, esses mecanismos revestem-se de características como prazer e diversão, mas, ao mesmo tempo, educam e produzem conhecimento. Para Giroux e McLaren,

...existe pedagogia em qualquer lugar onde o conhecimento é produzido, em qualquer lugar em que exista a possibilidade de traduzir a experiência e construir verdades, mesmo que essas verdades pareçam irremediavelmente redundantes, superficiais e próximas ao lugar comum. (1995, p. I4)

É nesse sentido que se considera a produção de imagens como um desses mecanismos educativos presentes nas instâncias socioculturais. As imagens não cumprem apenas a função de informar ou ilustrar, mas também de educar e produzir conhecimento.

A partir dessa compreensão da pedagogia da imagem, Kellner argumenta ainda que ler criticamente implica aprender a apreciar, decodificar e interpretar as imagens, analisando tanto a forma como elas são construídas e operam em nossas vidas, como o conteúdo que comunicam em situações concretas. $\bigcirc$ autor opõe-se à abordagem formal e anti-hermenêutica. Afirma que nossas experiências e nossas identidades são socialmente construídas e sobredeterminadas por uma gama variada de imagens, discursos e códigos. Para Kellner, 
a publicidade é um texto social multidimensional, com uma riqueza de sentidos que exige um sofisticado processo de interpretação e um importante indicador de tendências sociais, modas e valores. Ele concorda com Giroux (1996) que a pedagogia deve redefinir sua relação com a cultura e servir como veículo para sua interpretação.

Apesar do crescente interesse pelo visual, a expressão "leitura de imagem" não é consenso entre artistas, educadores, historiadores, sociólogos e antropólogos, já que para vários pesquisadores desses campos não é possível "ler" uma imagem. Afastando-se dessa polêmica, em uma vertente interacionista e significativa da leitura, Smith (1999) sugere que se evitem as intermináveis discussões semânticas sobre definições de leitura e se pense no processo da leitura. Para ele, os bens simbólicos produzidos pela humanidade são codificados de formas diversas, mas que mantêm uma estreita relação entre si e se expressam no que se convencionou chamar de "semiose" cultural, essa ampla rede de significações. A recepção desses bens simbólicos pode ser compreendida como leitura, na medida em que todo recorte na rede de significações é considerado um texto. Assim, é possível ler o traçado de uma cidade, um filme, uma coreografia. Imagem e escrita são códigos em constante interação.

No sentido de semiose cultural, Freire (1983) já sustentava que a leitura do mundo precede a leitura da palavra e, nesse caso, toda leitura é influenciada pela experiência de vida do leitor. Essa abordagem a partir da experiência do leitor é proposta também por Manguel (200l). Em uma perspectiva narrativa, o autor afirma que nenhuma narrativa suscitada por uma imagem é definitiva, exclusiva, pois o que vemos é sempre a imagem traduzida nos termos da nossa própria experiência. E propõe uma leitura que parta das emoções do leitor, ou seja, de como as emoções do leitor afetam e são afetadas pela leitura das imagens.

\section{CULTURA VISUAL}

Situando-se no marco dos Estudos Culturais, Bolin e Blandy (2003) opõem-se à denominação de "visual" para o trabalho dos docentes com as imagens, pois a consideram restritiva, tendo em vista o amplo leque de experiências que as imagens físicas e virtuais proporcionam. Esses autores recolocam a questão da predominância do visual e da relação desse sentido com ou so- 
bre os demais. Respondendo a essas observações, Mitchell (1995), em uma de suas primeiras publicações, já advertira que, apesar de a noção de "visual" constituir uma dimensão diferente da linguagem verbal, isso não implica que a cultura visual considere esse aspecto isoladamente, mas, ao contrário, a cultura visual inclui a relação com todos os outros sentidos e linguagens.

A questão levantada por Bolin e Blandy situa-se em uma corrente mais "restritiva" da cultura visual. Barnard (200I) identificou duas vertentes fundamentais nos estudos de cultura visual. A primeira, que no meu entendimento é a mais "restritiva", enfatiza o visual e trata de normatizar e prescrever seus objetos de estudo como sendo a arte, o design, as expressões faciais, a moda, a tatuagem e um longo etc. A outra vertente toma a cultura como traço definidor do estudo, e portanto se refere a valores e identidades construídos e comunicados pela cultura via mediação visual, como também à natureza conflituosa desse visual devido aos seus mecanismos de inclusão e exclusão de processos identitários.

Um dos representantes desta última vertente é Mirzoeff (2003). Segundo ele, a visualização é a característica do mundo contemporâneo, mas isso não significa que se conheça necessariamente aquilo que se observa. A distância entre a riqueza da experiência visual na cultura contemporânea e a habilidade para analisar esta observação cria a oportunidade e a necessidade de converter a cultura visual em um campo de estudo. Mirzoeff afirma que a cultura visual é uma "tática para estudar a genealogia, a definição e as funções da vida cotidiana pós-moderna a partir da perspectiva do consumidor, mais que do produtor" (p.20). Enfatiza que não se trata de uma história das imagens, nem depende das imagens em si mesmas, mas sim dessa tendência de plasmar a vida em imagens ou visualizar a existência, pois o visual é um "lugar sempre desafiante de interação social e definição em termos de classe, gênero, identidade sexual e racial" (p.20).

No sentido indicado por Mirzoeff, a cultura visual é uma estratégia para compreender a vida contemporânea, e não uma disciplina acadêmica. Lembra que a cultura pública dos cafés do século XVIII, exaltada por Jürgen Habermas, e o capitalismo impresso do mundo editorial do século $X I X$, descrito por Benedict Anderson, foram características particulares de um período e centrais para a análise produzida por esses autores, apesar das múltiplas alternativas que poderiam ter escolhido. À maneira desses autores, Mirzoeff procura plasmar a 
vida em imagens ou visualizar a existência para estudar a contemporaneidade. Ele busca compreender a resposta dos indivíduos e dos grupos aos meios visuais de comunicação em uma estrutura interpretativa fluida. Enfatiza que a noção de cultura visual é nova precisamente por centrar-se no visual como lugar onde se criam e se discutem significados. Assim, distancia-se das obras de arte, dos museus e do cinema para focalizar sua atenção na experiência cotidiana. Do mesmo modo que os estudos culturais tratam de compreender de que maneira os sujeitos buscam dar sentido ao consumo na cultura de massas, a cultura visual dá prioridade à experiência cotidiana do visual, interessase pelos acontecimentos visuais nos quais o consumidor busca informação, significado e/ou prazer conectados com a tecnologia visual. $\bigcirc$ autor define a tecnologia visual "como qualquer forma de dispositivo desenhado para ser observado e/ou para aumentar a visão natural, abarcando da pintura a óleo até a televisão e a Internet" (Mirzoeff, 2003, p. 19).

A cultura visual, nessa concepção, contém uma proposta bem mais ampla que a de leitura de imagens baseada no formalismo perceptivo e semiótico. Trabalhar nesse enfoque amplo é aceitar a capacidade das imagens de atuarem como mediadoras de "velhas e novas formas de poder, como também de ensaios contradiscursivos de novas formas de sociabilidade" (Moraza, 2004). Essa abordagem fundamenta-se em uma base socioantropológica, o que significa focalizar o conhecimento tanto nos produtores dessas experiências quanto no contexto sociocultural em que são produzidas.

As noções de visão e visualidade são básicas para esse entendimento da cultura visual. Walker e Chaplin (2002) definem a visão como o processo fisiológico em que a luz impressiona os olhos e a visualidade como o olhar socializado. Não há diferença entre o sistema ótico de um brasileiro, de um europeu ou de um africano, mas sim no modo de descrever e representar o mundo de cada um, pois eles têm maneiras próprias de olhar para o mundo o que, conseqüentemente, dá lugar a diferentes sistemas de representação.

Nessa mesma linha de raciocínio, Freedman $(2002,2003)$ mostra que nossas identidades se refletem e se definem nas maneiras como representamos a nós mesmos visualmente, do que vestimos ao que assistimos na televisão. Para essa autora, as práticas educativas com a cultura visual podem incluir tanto a discussão sobre um videojogo quanto as possíveis modificações no meio imediato, como, por exemplo, a decoração do quarto das/os educandas/os. 
Segundo Freedman, as/os educandas/os tomam consciência de que as imagens e os objetos portam significados e começam a se interessar por sua interpretação, procurando sugerir significados em suas próprias produções. E isso ocorre à medida que as/os educandas/os se empenham com maior afinco em contar histórias e fazer afirmações através de suas experiências.

Ainda segundo Freedman (2003), a cultura é a forma de viver e a cultura visual dá forma ao nosso mundo, ao mesmo tempo em que é nossa forma de olhar o mundo. Sua proposta de trabalho com a cultura visual pretende ser uma resposta razoável ao caráter cada vez mais interativo das artes visuais, que vão das Belas Artes às histórias em quadrinhos. A autora opõe-se ao elitismo das Belas Artes como uma linha divisória das práticas com imagens no contexto escolar, e destaca três objetivos que podem proporcionar os fundamentos de um enfoque social no trabalho com a cultura visual: o desenvolvimento de idéias, a visualização e a reflexão crítica. Ressalva que trabalhar com histórias em quadrinhos não significa copiar imagens e/ou personagens dessas produções, mas sim tentar "visualizar", a partir da narrativa dessas produções, uma outra sociedade que também enfrenta conflitos, e propor soluções para eles.

Sintonizada a essa vertente cultural, Chanda (2002) propõe uma aproximação dos artefatos visuais a partir da perspectiva do observador, da perspectiva histórico-cultural do artefato e da perspectiva do produtor. A autora argumenta que se nos aproximarmos de um artefato visual somente a partir de nossa visão individual teremos uma interpretação bastante restrita, pois os artefatos visuais constituem veículos perfeitos para descobrirmos como percebemos a nós mesmos e compreendemos o mundo, e como percebemos e compreendemos o outro. Isso nos coloca diante de um problema duplo, pois temos de tratar com culturas que muitas vezes são alheias a nós e com culturas que estão ao mesmo tempo próximas e separadas de nós. As descrições e as interpretações de um artefato visual com os olhos de alguém que não está familiarizado com a cultura da qual o artefato procede refletirão unicamente os conceitos filosóficos, os ideais e a história do/a observador/a, e não os da cultura de origem do artefato.

As descrições do artefato visual desvelam, de acordo com Chanda, os medos, os estereótipos, e as idéias que o/a observador/a do artefato leva consigo no olhar. Para a autora, contemplar um artefato visual com os olhos do Outro oferece uma oportunidade única de experimentarmos os comportamen- 
tos e as formas de pensar que criam as diferenças. Ela sugere um segundo movimento: olharmos para nós mesmos do marco contextual do Outro. Para exemplificar, pergunta quais são os aspectos da cultura negra que fazem parte da cultura americana em geral e que permitiriam aos americanos afirmar que em muitos aspectos são diferentes, mas que em outros são próximos. Esse deveria ser, segundo ela, o objetivo de uma educação visual multicultural.

No Brasil, Richter (2003) mostra que as questões do multiculturalismo têm chegado por muitos caminhos, a partir das discussões que se iniciaram nos Estados Unidos e na Europa. Observa que os Parâmetros Curriculares Nacionais propõem o pluralismo cultural como um dos temas transversais que devem ser trabalhados nos currículos escolares da Educação Básica, mas não chegam a discutir questões básicas. Ela cita como exemplo a questão do gênero nas práticas visuais. Do seu ponto de vista, essa é uma das questões fundamentais a serem discutidas nas práticas visuais do contexto escolar, visto que os padrões estéticos familiares que as crianças levam para a escola são construídos a partir dos padrões estéticos femininos. Ela afirma que as práticas visuais nas escolas do país costumam estar imbuídas dos códigos hegemônicos norte-americanos e europeus, com uma supervalorizada visualidade desenvolvida por brancos, do sexo masculino, europeus ou de origem européia, segundo os cânones formais da modernidade, o que acaba excluindo aquela visualidade não condizente com esse padrão. Assim, as práticas visuais no contexto escolar caracterizariam-se por uma atitude em que os padrões culturais e estéticos da comunidade e da família são respeitados e inseridos na educação, e aceitos como códigos básicos a partir dos quais se deve construir a compreensão e imersão em outros códigos culturais.

Outro educador que se situa nessa vertente cultural é o australiano Paul Duncun (2002). Para ele, a cultura visual vincula-se aos estudos culturais nas questões relacionadas às práticas significantes, tanto em termos das experiências vividas pelas pessoas como da dinâmica estrutural da sociedade. Esta se estrutura em torno do domínio, e as práticas significantes são sempre um meio de estabelecer e manter o poder; porém, as pessoas podem resistir e negociar o significado dessas práticas por si mesmas. $\bigcirc$ autor rejeita a noção de cultura como um refinamento pessoal, ou como obras de uma sensibilidade determinada, pois isto representa apenas uma parte muito seletiva da cultura. Rejeita igualmente a noção antropológica de cultura como prática de vida, por 
considerá-la muito ampla. Adota uma concepção de cultura como práticas significantes, não como objetos específicos, mas sim como as relações sociais, valores, as crenças e as práticas das quais os objetos são uma parte constitutiva.

Em meio à saturação visual da vida contemporânea, seja em seus aspectos de vigilância, espetáculo, prazer, controle ou manipulação, Duncun (2003) oferece algumas pistas sobre como trabalhar com a cultura visual em ambientes de aprendizagem. Em sua abordagem, os artefatos visuais podem ser os mais variados, das fotografias pessoais aos suvenires da cidade. No trabalho com as fotografias familiares, propõe tanto a aprendizagem dos códigos desse tipo de fotografia como a reflexão sobre como e por que esses códigos se transformam. Para isso, sugere que as/os educandas/os falem de suas experiências ao serem fotografadas/os ao mesmo tempo em que examinam pinturas das famílias de séculos passados, observando diferenças formais nas posturas, na expressão facial, nas vestimentas, no cenário, na ação e o que isso pode implicar nas relações familiares. Também questiona se a fotografia familiar é sexista, se exclui, na mesma medida em que inclui, e portanto estrutura uma falsa idéia de vida familiar, se pode chegar a ser um jogo de poder a partir de um lado da câmara fotográfica ou de ambos os lados.

\section{COMPREENSÃO CRÍTICA DA CULTURA VISUAL}

Hernandez (2000) adiciona a expressão compreensão crítica à abordagem da cultura visual. Para esse autor, o vocábulo "crítica" significa avaliação e juízo que resultam de diferentes modelos de análise (semiótico, estruturalista, desconstrucionista, intertextual, hermenêutico, discursivo). Ele fundamenta sua proposta em idéias provenientes do pós-estruturalismo e do feminismo pósestruturalista. Prefere utilizar os termos representações e artefatos visuais ao invés de imagens. Utiliza o conceito de cultura no sentido socioantropológico próximo da experiência cotidiana de qualquer grupo atual e/ou passado. Percebe a importância da Cultura Visual não só como campo de estudo, mas também em termos de economia, negócios, tecnologia, experiências da vida diária, de forma que tanto produtores como intérpretes possam se beneficiar do seu estudo.

A compreensão crítica aborda a cultura visual como um campo de estudo transdisciplinar multireferencial que pode tomar seus referentes da arte, da 
arquitetura, da história, da psicologia cultural, da psicanálise lacaniana, do construcionismo social, dos estudos culturais, da antropologia, dos estudos de gênero e mídia, sem fechar-se nessas ou somente sobre essas referências. Essa proposta ampla e aberta enfatiza que o campo de estudos não se organiza a partir de nomes de artefatos, fatos e ou sujeitos, mas sim de seus significados culturais, vinculando-se à noção de mediação de representações, valores e identidades. Para Hernandez, um estudo sistemático da cultura visual pode proporcionar uma compreensão crítica do seu papel e de suas funções sociais, como também de suas relações de poder, indo além da apreciação ou do prazer que as imagens nos proporcionam.

Hernandez (no prelo) entende o campo de estudo como sendo móvel, pois a cada dia se incorporam novos aspectos relacionados tanto às representações quanto aos artefatos visuais, que rapidamente tornam obsoletas as aproximações restritivas. Nessa perspectiva, não há receptores nem leitores, mas sim construtores e intérpretes, na medida em que a aproximação não é passiva nem dependente, mas sim interativa e condizente com as experiências que cada sujeito vive no seu dia-a-dia. Uma primeira meta a ser perseguida nessa abordagem seria explorar as representações que as pessoas constroem da realidade a partir das suas características sociais, culturais e históricas, ou seja, compreender o que se representa para compreender as próprias representações.

Um trabalho na linha da compreensão crítica da cultura visual "não pode ficar à margem de uma reflexão mais ampla sobre o papel da escola e dos sujeitos pedagógicos nesses tempos de mudança" (Hernandez, 2002, p.3). Nós, educadoras e educadores, temos de estar atentos ao que se passa no mundo, seja nos saberes, na sociedade ou nos sujeitos, e responder com propostas imaginativas, transgressoras, que possibilitem às/aos educandas/os elaborar formas de compreensão e de atuação na parcela do mundo que lhes toca viver, de forma que possam desenvolver seus projetos de vida. A situação que o/a educador/a cria para iniciar o processo de aprendizagem sinaliza sua orientação educativa, o lugar que destina à/ao educanda/o e a si mesma/o.

Não cabe mais ao/à educador/a se perguntar o que as/os educandas/os não sabem e propor-se a ensinar-lhes, e sim o que já sabem e como é possível ampliar as conexões, para que, juntos, possam organizar outros discursos com os saberes-mosaico que todos possuem. A abordagem da compreensão 
crítica não enfatiza nem as representações nem os artefatos visuais, pois, ao se trabalhar na perspectiva de projetos de trabalho, o mais relevante é a construção de uma história que se compartilha e que será narrada. Mais do que pensar em representações e artefatos, interessa ao/à educador/a saber o que o grupo de trabalho, que inclui educandas/os e educadoras/es, quer aprender e o que pode aprender.

Essa abordagem requer uma mudança na forma como se organiza tradicionalmente o conhecimento escolar. Sugere às/aos educadoras/es que estejam especialmente atentos aos objetos da Cultura Visual do grupo, ou seja, as imagens que estão nas capas dos cadernos e pastas das/os educandas/os, as revistas que lêem, os programas de televisão a que assistem, seus conjuntos musicais e jogos preferidos, suas roupas e seus ícones populares. A compreensão crítica dessas representações e artefatos visuais implica diferentes aspectos, tais como:

- Histórico-antropológico: as representações e artefatos visuais são frutos de determinados contextos que os produzem e legitimam. Por isso, é necessário ir além de uma abordagem perceptiva daquilo que se vê na produção, para estabelecer conexões entre os significados dessa produção e a tradição: valores, costumes, crenças, idéias políticas e religiosas que as geraram.

- Estético-artístico: este aspecto refere-se aos sistemas de representação. $\bigcirc$ aspecto estético artístico é compreendido em relação à cultura de origem da produção, e não em termos universais, pois o código europeu ocidental não é o único válido para a compreensão crítica da cultura visual.

- Biográfico: as representações e artefatos fomentam uma relação com os processos identitários, construindo valores e crenças, visões sobre a realidade.

- Crítico-social: representações e artefatos têm contribuído para a configuração atual das políticas da diferença e das relações de poder.

Esses aspectos não são seqüenciais, mas estão interconectados, e cabe às/aos educadoras/es fomentar sua compreensão, propondo que se estabeleçam relações entre o que se produz e os contextos de produção, distribuição 
e consumo, e que se procure perceber seus efeitos na construção dos processos identitários. Como pistas de caminhos possíveis em um trabalho para a compreensão crítica da cultura visual, Hernandez $(2000,2002)$ sugere:

- explorar os discursos sobre os quais as representações constroem relatos do mundo social e favorecem determinadas visões sobre ele e sobre nós mesmos;

- questionar a tentativa de fixar significados às representações e como isso afeta nossas vidas;

- discutir as relações de poder que se produzem e se articulam por meio das representações, e que podem ser reforçadas pela maneira de ver e produzir essas representações;

- elaborar representações por procedimentos diversos, como forma, resposta e modo de diálogo com as representações existentes;

- construir relatos visuais utilizando diferentes suportes relacionados com a própria identidade e contexto sociocultural que ajudem a construir um posicionamento.

\section{PERGUNTAS TRAMADAS}

Como se pode ver, nesse percurso pelos referenciais da arte, antropologia, educação, história e sociologia, a abordagem da cultura visual em sua vertente cultural amplia a proposta formalista estética e semiótica da leitura de imagens. Por se tratar de uma abordagem multireferencial e transdisciplinar, um trabalho de compreensão crítica da cultura visual nos mais variados ambientes de aprendizagem pode ser desenvolvido por qualquer educador/a que deseje e se disponha a problematizar as representações sociais de menina, menino, muIher, homem, família, criança, adolescente, adulto, velho, pobre, rico, preto, branco, professor/a, estudante, escola, entre tantas outras possíveis, nas imagens dos livros didáticos, dos cadernos, das revistas, dos outdoors, dos videojogos, da televisão, dos cartões postais, dos brinquedos, das obras de arte etc.

O foco de um trabalho de compreensão crítica da cultura visual não está no que pensamos dessas representações, mas sim no que, a partir delas, possamos pensar sobre nós mesmos. $\bigcirc$ que falam de mim as representações de mulher, trabalhadora, professora, esposa, consumidora? $\bigcirc$ que não falam de 
mim? $\bigcirc$ que falam e não falam das pessoas iguais a mim e diferentes de mim? O que posso pensar de mim a partir dessas diferentes representações? Por que determinadas representações são sempre recorrentes? Que interesses são satisfeitos com essas representações?

A representação reiterada de determinados temas e ou grupos sociais acabam por naturalizar e simbolizar um determinado grupo social e/ou um tema como normal, aceitável. Como nós, as/os educadoras/es, temos sido representadas/os? Como nós, as/os educadoras/es temos nos representado? Quais as diferenças formais nas posturas, expressões faciais, vestimentas, cenários e ações das/os educadoras/es em representações dos séculos XVIII, XIX, XX e $X X I$ ? E nas representações das/os estudantes? De que maneira essas representações vêm tentando e/ou conseguindo "fixar" determinados significados para esses papéis? Como foram geradas essas representações? Por quem, para quem e por que foram geradas? Que cenários têm sido privilegiados nas representações do espaço escolar nesses últimos três séculos? O que ainda não incluímos nas representações da escola? Que idéias de ambiente de aprendizagem essas representações acabam por fixar?

Penso que trabalhar na perspectiva da compreensão crítica da cultura visual pode nos auxiliar a encontrar algumas frestas que, talvez, dêem passagem a outras formas de compreensão da realidade, de representações que não as hegemônicas, e a discutir uma representação reiterada de passividade, indiferença, apatia e rotina dos sujeitos em seus ambientes de aprendizagem.

\section{REFERÊNCIAS BIBLIOGRÁFICAS}

ARNHEIM, R. Arte e percepção visual: uma psicologia da visão criadora. São Paulo: Edusp, Pioneira, 1989.

BARNARD, M. Approaches to understanding visual culture. New York: Palgrave, $200 \mathrm{I}$. BARRET, T. Visual culture. Art Education, v.56, n.303, p. 17-24, mar.2003.

BOLIN, P. E.; BLANDY, D. Beyond visual culture: seven statements of suport for material culture studies in art education. Studies in Art Education: a Journal of Issues and Research, v.44, n.3, p.246-263, 2003.

BRASIL. Ministério da Educação e Cultura. Parâmetros curriculares nacionais. arte ( $\left.\right|^{\mathrm{a}}$ a $4^{\mathrm{a}}$ série). Brasília, 1997. 
CARDOSO, C. F.; MAUD, A. M. História e imagem: os exemplos da fotografia e do cinema. In: CARDOSO, C. F; VAINFAS, R.(org.) Domínios da história: ensaios de teoria e metodologia. Rio de Janeiro: Campus, 1997. p.40I-4I7.

CHANDA, J. Ver al otro a través de nuestros proprios ojos: problemas en la educación multicultural: el estado de la pedagogia artística multicultural. In: JORNADAS CAIXA FÓRUM. Barcelona, 2002.

CRUZ, R. Como enseñar arte a través de los medios. Revista Comunicar, v.9, n. I7, p. I66169, oct.2001.

CUNHA, L. N.. O Documento fotográfico: um caminho a mais para o conhecimento da presença negra na escola pública brasileira. Disponível em: http://www.anped.org.br/0203t.pdf. Acesso em: 15.12.2001.

DONDIS, D. A Sintaxe da linguagem visual. São Paulo: Martins Fontes, 1991.

DUNCUN, P. Clarifying visual culture art education. Art Education, v.55, n.328, p.6- I I, may 2002.

Visual culture in the classroom. Art Education, v.56, n.303, p.25-32, mar.2003.

FABRIS, A. Redefinindo o conceito de imagem. Revista Brasileira de História. São Paulo, v. I 8, n.35, p. 217-224, 1998.

FELDMAN-BIANCO, B.; LEITE, M. L M. (orgs.) Desafios da imagem: fotografia, iconografia e vídeo nas ciências sociais. Campinas: Papirus, 1998.

FRAISE, E.; POUMPOUGNAC, J.-C.; POULAIN, M. Representações e imagens da leitura. São Paulo: Ática, 1997.

FREEDMAN, K. Cultura visual e identidad. Cuadernos de Pedagogía. Barcelona, n. 31 2, p.596I, 2002.

The Importance of student artistic production to teaching visual culture. Art Education, v.56, n.303, p.38-43, mar.2003.

FREIRE, P. A Importância do ato de ler. São Paulo: Cortez, 1983.

GIROUX, H. Placeres inquietantes. Barcelona: Paidos, 1996.

GIROUX, H.; McLAREN, P. Por uma pedagogia crítica da representação. In: SILVA, T. T.; MOREIRA, A. F. (orgs.) Territórios contestados. Petrópolis: Vozes, 1995, p. I44-58.

HERNANDEZ, F. Cultura visual, mudança educativa e projeto de trabalho. Porto Alegre: Artmed, 2000. 
Espigadores de imágenes. Barcelona: Octaedro. (no prelo).

Más allá de los limites de la escuela: un diálogo entre emergencias sociales y cambios en las artes visuales y en la educación. In: JORNADAS FUNDACIÓN LA CAIXA, 2002.

HOUSEN, A. Validating a measure of aesthetic: development for museums and schools. ILVS Review. Massachusetts College of Art, v.2, n.2, p.213-237, 1992. Disponível em: http:/ /wnw.vue.org/documents/validating.html. Acesso em: dez. $200 \mathrm{l}$.

JOLY, M. Introdução à análise da imagem. São Paulo: Papirus, 1996.

KELLNER, D. Lendo imagens criticamente: em direção a uma pedagogia pós-moderna. In: SILVA, T. T. (org.) Alienígenas na sala de aula: uma introdução aos estudos culturais em educação. Petrópolis: Vozes, 1995. p. 104-31.

LEITE, M. L. M. Imagem e educação. In: SEMINÁRIO PEDAGOGIA DA IMAGEM NA PEDAGOGIA. Anais. Rio de Janeiro: UFF, 1996. p.66-68.

MANGUEL, A. Lendo imagens. São Paulo: Companhia da Letras, 2001.

MIRZOEFF, N. Una introducción a la cultura visual. Barcelona: Paidós, 2003.

MITCHELL, W. J. T. Que és la cultura visual. Princenton: Irving Lavin, Institute for Advanced Study, 1995. Disponível em: http://www.ub.es/boletin. Acesso em: jun.2003.

MORAZA, J. L. Estudios visuales y sociedad del conocimiento. In: CONGRESO INTERNACIONAL DE ESTUDIOS VISUALES, I. Madrid, fev. 2004. Disponível em: http:// www.estudiosvisuales.net. Acesso em: fev.2004. [Trabalhos iniciais].

OSTROWER, F. Acasos e criação artística. Rio de Janeiro: Campus, 1990.

Criatividade e processos de criação. Petrópolis: Vozes, 1987.

. Universos da arte. Rio de Janeiro: Campus, 1983.

OTT, R. W. Art in education: an international perspectiv. Pennsylvania: Pennsylvania State University Press, 1984.

PARSONS, M. J. Compreender a arte. Lisboa: Presença, 1992.

RICHTER, I. Interculturalidade e estética do cotidiano no ensino das artes visuais. São Paulo: Mercado de Letras, 2003.

ROSSI, M. H. Imagens que falam. Porto Alegre: Mediação, 2003.

SAMAIN, E. Questões heurísticas em torno do uso das imagens nas ciências sociais. In: FELDMAN-BIANCO, B.; LEITE, M. L M. (orgs.) Desafios da imagem: fotografia, iconografia e vídeo nas ciências sociais. Campinas: Papirus, 1998. p.5 I-64. 
SANTIBÁÑEZ, J.; VALGAÑÓN, F. Arte visual, hipermídia y lectura de imágenes. Revista Comunicación y Pedagogia. Barcelona, n. 178, p.59-62, 2000.

SILVA, T. T. da.; MOREIRA, A. F. (orgs.) Territórios contestados. Petrópolis: Vozes, 1996.

SMITH, F. Leitura significativa. Porto Alegre: Artes Médicas, 1999.

VALLE GASTAMINZA, F. del. La Documentación de los medios informativos. In: GALDÓN LÓPEZ, G. Perfil historico de la documentación en la prensa de información general. Pamplona: Eunsa, 2002. p. $179-205$.

WALKER, J. A.; CHAPLIN, S. Una introducción a la cultura visual. Barcelona: Octaedro, 2002.

Recebido em: outubro 2004

Aprovado para publicação em: junho 2005 